\title{
When Is a Youth's Debt to Society Paid? Examining the Long-Term Consequences of Juvenile Incarceration for Adult Functioning
}

\author{
Amanda B. Gilman • Karl G. Hill • J. David Hawkins
}

Received: 16 October 2014 / Revised: 28 January 2015 / Accepted: 2 February 2015 /

Published online: 26 February 2015

(C) Springer International Publishing AG 2015

\begin{abstract}
Purpose This study aimed to examine the long-term consequences of juvenile incarceration on functioning in adulthood (ages 27-33).

Methods Propensity score analysis was used to compare incarcerated youth with those who were never incarcerated in a subsample of individuals who had experienced at least one police contact in adolescence. Data were drawn from the Seattle Social Development Project (SSDP), a multiethnic, gender-balanced community sample.

Results Youth who were incarcerated in adolescence were more likely to experience incarceration at ages 27,30 , or 33 , more likely to meet criteria for alcohol abuse or dependence, and more likely to be receiving public assistance than similar youth who were never incarcerated.

Conclusions Results show that juvenile incarceration is not only ineffective at reducing criminal behavior later in life but that there are also unintended consequences for incarceration beyond the criminal domain. Furthermore, it appears that once a youth becomes involved in the juvenile justice system, there is a higher likelihood that he/she will remain tethered to the criminal justice system through the transition to adulthood. Given these long-term deleterious outcomes, it is recommended that suitable alternatives to juvenile incarceration that do not jeopardize public safety be pursued.
\end{abstract}

Keywords Incarceration - Life course consequences · Adolescence

\section{Introduction}

The juvenile delinquency court in the USA was originally founded in an attempt to distinguish between adult and youthful offenders, emphasizing that youth were in need of protection, guidance, and rehabilitation, rather than punishment [1]. However, since

A. B. Gilman $(\varpi) \cdot$ K. G. Hill $•$ J. D. Hawkins

Social Development Research Group, School of Social Work, University of Washington, 9725 3rd Ave.

N.E., Suite 401, Seattle, WA 98115, USA

e-mail: abg5@uw.edu 
the first juvenile delinquency court was established in Chicago in 1899, the juvenile justice system has grown increasingly punitive and has begun to resemble the adult criminal justice system in many ways, including the increased use of incarceration [2].

While the most recently available data [3] show that as of 2011, juvenile incarceration rates have declined by $42 \%$ from 1997, the USA still has the highest rate of juvenile incarceration among industrialized nations [4]. For every 100,000 youth in the US population, 196 were incarcerated in 2011.

With so many youth experiencing incarceration in the USA, it is important for juvenile justice and social welfare policies and practices to understand how this sanction ultimately affects the life course trajectories of these youth. Is juvenile incarceration truly rehabilitative, as it was originally intended to be? Or, as many have claimed (see literature review below), are the effects of incarceration actually iatrogenic, increasing the likelihood of future offending? Finally, are there unintended consequences of incarceration beyond criminal outcomes, (e.g., for mental health and financial security)?

There are several theoretical explanations for why incarceration might be ineffective or even deleterious with regard to criminal outcomes and also why it might be related to negative outcomes in other areas of adult functioning. Greve ([5], p. 27) writes, "Youth incarceration is almost by definition a (harsh kind of) developmental intervention. Thus, its impact and consequences have to be evaluated from a developmental point of view." Our theoretical framework takes a developmental perspective and draws on the life course paradigm [6-8] and labeling theory $[9,10]$ to examine how incarceration affects development through the life course.

The life course perspective, broadly speaking, addresses within-individual processes over time and across developmental stages. Life course criminologists have often focused on offending across the life span. While offending in adolescence is a very strong predictor of offending in adulthood, the majority of youthful offenders desist. Gilman et al. [11] found that $68 \%$ of those who self-reported property offenses in adolescence and $67 \%$ of those who self-reported violent offenses in adolescence had desisted from these behaviors in adulthood. However, one task for life course criminologists has been to discover why some youth persist in offending. In their theory of cumulative disadvantage, which uses the life course perspective and labeling theory together to help understand stability in criminal behavior, Sampson and Laub [12] contend that the relationships between childhood predictors of criminal behavior and adult crime are mediated by "institutions of informal and formal social control, especially in the transition to adulthood" (p. 10). In addition, they write, "The theory specifically suggests a 'snowball' effect - that adolescent delinquency and its negative consequences (e.g., arrest, official labeling, incarceration) increasingly 'mortgage' one's future, especially later life chances molded by schooling and employment" ( $p$. 15). It could be that youth who might otherwise desist from criminal behavior as they transition to adulthood face a turning point when they are incarcerated, which may alter their opportunity structures during the critically important transition to adulthood and produce negative consequences in both criminal and non-criminal domains.

Labeling theory $[9,10]$, which has been described as "the one theoretical perspective in criminology that is inherently developmental in nature" ([12], p. 3), is helpful in unpacking how incarceration may serve as a negative turning point in youths' lives. In a normative transition from adolescence to adulthood, youth are expected to finish their 
education, engage in gainful employment, find a romantic partner, and start a family [13]. Labeling theory scholars have identified three mechanisms through which the criminal label operates to affect future consequences [14], all of which help to explain why incarceration during adolescence could be severely disruptive to the normative path and a successful transition to adulthood.

First, some theorists have argued that following a labeling event such as incarceration, the individual internalizes the criminal label, eventually taking on the identity assigned to him/her (e.g., [15-18]). This internalization process might take on the form of shifts in identity and changes in beliefs and attitudes. Second, as a result of the criminal label, individuals may find that their social networks have changed, either by choice or by force, in such a way that they have new or increased associations with antisocial peers (e.g., [16, 18]). Finally, some theorists assert that criminal labels are associated with decreased social and structural opportunities (e.g., [19, 20]). This reduction in conventional opportunities, such as education and employment, pushes the individual further into the criminal lifestyle. Becker [21] wrote, "Labeling places the actor in circumstances which make it harder for him to continue the normal routines of everyday life and thus provoke him to 'abnormal' actions" (p. 179). These circumstances can be formal (e.g., laws prohibiting convicted felons from voting or receiving financial aid) or informal (e.g., employers refusing to hire or landlords refusing to rent to individuals with a criminal record). Thus, it is also quite reasonable to expect that the effects of incarceration would "cascade" into other non-criminal domains of adult functioning, including mental health and financial security [22].

\section{Literature Review}

Several studies have examined the consequences of juvenile justice system involvement more broadly, finding that involvement is positively associated with later offending [20, $23,24]$ and unemployment $[25,26]$. However, in this paper, we focused on studies that examined the effects of incarceration explicitly. Similarly, given our interest in understanding how incarceration in adolescence affects functioning in a later developmental period, we reviewed studies that examined the effects of incarceration when that incarceration occurred before or during the transition to adulthood. Thus, studies summarized here included a mixed sample of juveniles and young adults or explicitly studied incarceration that occurred before the age of 18 .

Using a lifetime measurement of incarceration (including both adolescence and early adulthood), researchers have found that incarceration is related to fewer job opportunities [27-31], decreased wages [27, 32, 33], housing insecurity [34], lower rates of marriage [29, 35, 36], family instability [13, 35-37], poor health [38-40], and mental health problems [41]. While informative and valuable, these studies do not distinguish between juvenile and adult incarceration. For example, many of the studies cited above used the National Longitudinal Study of Youth (NLSY79), which follows a cohort through adolescence and early adulthood (participants were between the ages of 14 and 22 at the beginning of the study), to examine the consequences of incarceration (e.g., [29, 33, 35-40, 42]). Thus, some participants had likely already transitioned into adult roles prior to incarceration, which would have different consequences for adult functioning than incarceration during adolescence. In the current study, we were particularly 
interested in understanding the unique effects of juvenile incarceration on adult functioning, as adolescence is a critical time of preparation for the transition to adulthood [43].

Those studies that have limited their sample to juveniles to examine the consequences of incarceration show mixed results on several outcomes of interest, and encourage more research, especially with regard to long-term outcomes. First, we discuss studies that examine proximal consequence of incarceration. In a descriptive study, Abram et al. [44] found that more than one fifth of former juvenile detainees had significant impairment in functioning 3 years post-incarceration. In separate studies, both Hjalmarsson [45] and Aizer and Doyle [46] found that juvenile incarceration was related to a lower likelihood of high school graduation. On the other hand, Hjalmarsson [47] found that incarceration was actually related to lower recidivism when incarcerated youth were compared to youth who had been adjudicated but received a disposition other than incarceration. White et al. [48] did not find significant relationships between incarceration and anxiety and depression in a community youth sample.

While the results of studies examining the short-term consequences of juvenile incarceration are mixed, there is somewhat clearer evidence supporting the negative long-term consequences of juvenile incarceration, though more research is needed. Using a sample of institutionalized youth, as well as a comparison community sample of youth residing in a private residence, Lanctot et al. [13] found that juvenile institutionalization was linked to socioeconomic disadvantage, job and interpersonal instability, drug-related problems, and depression in the late 20 s, even when controlling for prior self-reported delinquency. Studying a sample of over 35,000 juvenile offenders, Aizer and Doyle [46] utilized an instrumental variable technique (using the inclination for randomly assigned juvenile judges to incarcerate or not), to study the relationship between juvenile incarceration and adult incarceration. They found that there was a strong positive relationship between incarceration in adolescence and in adulthood. Thus, there is some evidence that juvenile incarceration is related to negative outcomes in adulthood.

\section{The Current Study}

This study fills gaps in the literature in several ways. First, we focused specifically on the effects of juvenile incarceration. For youth who are incarcerated, developmental and social transitions and milestones can be disrupted in a time of preparation for the important transition to adulthood. Indeed, Pettit and Western [49] write, "From the life course perspective, prison represents a significant re-ordering of the pathway through adulthood that can have lifelong effects" (p. 154). Barrick [14] concluded from her review that juveniles were more susceptible than adults to the negative effects of labeling after involvement in the criminal justice system, as evidenced by increased recidivism.

Second, we examined the long-term consequences of juvenile incarceration, focusing on seven outcomes at ages 27-33: criminal behavior, incarceration, alcohol abuse/ dependence, drug abuse/dependence, depression, anxiety, and welfare receipt. Third, we used a sophisticated and rigorous analytic strategy, propensity score weighting, to adjust for confounding variables that might actually be driving incarceration and the 
observed outcomes. The present study uses a propensity weighting approach that renders the incarcerated and non-incarcerated comparison juveniles equivalent on a broad range of potential confounding background characteristics (both demographics as well as risk and protective factors), thus increasing confidence that the observed differences between these groups are due to juvenile incarceration specifically.

\section{Method}

Sample

This study used longitudinal data from the Seattle Social Development Project (SSDP) to examine the long-term consequences of juvenile incarceration. SSDP consists of a multiethnic community sample of males and females followed prospectively from 1985, when participants were in the fifth grade, into adulthood. A total of 808 fifthgrade students attending 18 elementary schools serving high-crime neighborhoods of Seattle in the fall of 1985 constitute the longitudinal sample. Schools were selected based on neighborhood crime statistics. Feeder elementary schools for those high-crime neighborhoods were selected and approached for participation. Due to mandated bussing at the time, these schools and this sample also included students from other parts of the city. Thus, the study oversamples children from high-risk neighborhoods but is not limited to these children. The 18 elementary schools represented approximately one quarter of the total number of elementary schools in Seattle at that time. Approximately $77 \%$ of the parents of fifth-grade students in these 18 schools consented to participation. Of the 808 students, 396 (49\%) were female, 345 (49.9\%) were European American, 177 (25.6\%) were African American, 130 (18.8 \%) were Asian American, and 40 (5.8\%) were Native American. Of these, about $5 \%$ were Hispanic. A considerable portion of participants came from low-income households. The median annual family income in 1985 was approximately $\$ 25,000$, and $46 \%$ of parents reported a maximum family income of less than $\$ 20,000$ per year. More than half of the student sample (52\%) had participated in the National School Lunch/School Breakfast Program in the fifth, sixth, or seventh grade.

\section{Procedures}

Data used in the present study were obtained from youth and parent surveys and official court records. Survey data were initially collected in 1985 when participants were in fifth grade and an average age of $10(M=10.3, \mathrm{SD}=0.52)$, then in the spring of each year thereafter through tenth grade, and again in 12th grade. In adulthood, participants have been interviewed approximately every 3 years. In grades 5 and 6 , surveys were group-administered questionnaires completed in the classroom. Youth who left the schools in the study were individually interviewed. Starting in grade 7 (1988), all students were individually interviewed, predominantly in person. The interviews asked for the participant's confidential responses to a variety of questions regarding peer, family, community, and school. The interviews lasted about $1 \mathrm{~h}$. Early in the study, youth received a small incentive (e.g., an audiocassette tape) for their participation and later received monetary compensation. Juvenile court records were obtained from 1985 
through adulthood. All data collection procedures have been approved by the University of Washington Institutional Review Board.

For the current study, only those individuals who ever had a police contact in adolescence were included in the analyses $(n=325)$. The purpose of this strategy, as explained below, was to create a comparison group that was as similar as possible to the incarcerated group with regard to background risk characteristics, behavior, and risk of incarceration. It should be noted that by comparing youth who were incarcerated with youth who had a police contact but possibly received some other sanction, we are examining the relative effect of labeling, rather than the absolute effect.

Police contact was measured using both self-reported and official court data. An official referral to the juvenile court would result in a record. However, any contact with the police due to delinquent or illegal behavior that did not result in a court referral would not be recorded in the official data. Therefore, we also used a self-reported variable measured at each data collection point through 12th grade that asked whether the respondent had ever been "picked up or arrested by the police." Thus, if an individual ever reported having been arrested or picked up by the police or had an official record of a court referral, he/she was included in the current study.

\section{Sensitivity Analyses}

A portion of the sample was exposed to a multicomponent preventive intervention in elementary grades, consisting of teacher training, parenting classes, and social competence training for children (see [50] for description and analysis of the intervention effects). Although differences in prevalences and means have been observed between intervention and control groups, prior analyses have shown few differences in the covariance structures of the groups [51-53]. To test possible differences in etiology between the groups, we examined a multiple-group covariance structure model constraining the covariance parameter estimates between predictors and outcomes in the study to be equal across intervention groups. This constrained model fit the data well (e.g., root mean square error of approximation $[\mathrm{RMSEA}]=0.04$ and comparative fit index $[\mathrm{CFI}]=0.95)$, and the results suggested no substantial between-group differences in the relationships of interest in this report, supporting a single-group analysis involving participants from all intervention conditions.

\section{Measures}

\section{Incarceration}

A strength of the SSDP dataset is the availability of official incarceration data provided by juvenile courts throughout the state of Washington. All arrests and subsequent incarcerations resulting from adjudication throughout adolescence were reported. If a youth had an official court record that indicated that he/she had been incarcerated, the youth was coded as (1), otherwise (0). Official data on incarceration were only available for those youth who were adjudicated by the court and received a disposition that included serving time in a juvenile detention center or a state juvenile corrections institution in Washington State. Thus, the incarceration group $(n=108)$ did not include youth who may have been detained for a short amount of time prior to adjudication or youth who were incarcerated in another state. 


\section{Adult Outcomes}

We investigated outcomes in several domains, measured at ages 27, 30, and 33 (in the years 2002, 2005, and 2008). If a respondent endorsed an outcome at either of the three time points, he/she was coded (1), otherwise (0). Crime was a measure of whether the respondent reported committing at least one violent or property offense in the past year at age 27,30 , or 33 . Incarceration was a self-reported measure of having spent time in jail or prison in the past year. Respondents were asked a series of questions about their drug and alcohol use. Individuals were coded with a (1) for drug abuse or dependence if they met DSM-IV criteria [54] for either dependence or abuse during the past year at ages 27,30 , or 33, and (0) if they never met criteria for either during this time frame. The same coding scheme was used for alcohol abuse or dependence. Similarly, mental health was measured with variables indicating whether respondents met diagnostic criteria, based on the DSM-IV [54] for major depression or generalized anxiety disorder at age 27, 30, or 33. Finally, welfare receipt was a self-reported measure of receipt of public assistance in the past year at age 27,30 , or 33 .

\section{Confounding Variables}

In an examination of the consequences of incarceration, it is essential to adequately control for potential confounds due to factors that might affect selection into the "treatment" (incarceration) group. For the present study, we selected a broad range of factors shown to be associated with juvenile incarceration. These measures were then used to estimate the propensity score, as described in the following section.

\section{Confounding Variables: Delinquency and Drug use}

In a review of the research on criminal labeling, Barrick [14] concluded that the most robust and sophisticated measures of prior delinquency are those which use a weighted measure that accounts for both frequency and severity of criminal behavior. Thus, to assess prior delinquency in this study, we used a count of the past-year frequency of self-reported delinquent acts and then weighted each act by severity (one for minor, two for moderate, and three for serious delinquency). Minor acts of delinquency included acts such as picking a fight, drawing graffiti, and stealing something worth less than $\$ 5$. Moderate delinquency included acts such as hitting parents, damaging or destroying property, and stealing something worth less than $\$ 50$. Serious delinquency included acts such as using a weapon or force to get something, breaking into a building, drug selling, and stealing something worth more than $\$ 50$. A value was calculated for each youth for each survey year from fifth through tenth grade and again in 12th grade. For those youth who were never incarcerated, these scores were averaged across adolescence through 12th grade. For those youth who were incarcerated, delinquency was calculated to establish temporal ordering with incarceration. That is, prior delinquency was calculated by averaging delinquency across years through the year in which the first incarceration occurred. For example, if a youth was first incarcerated in eighth grade, his/her delinquency score was an average of fifth, sixth, seventh, and eighth grade scores. For those who experienced their first incarceration in 11th grade, when 
survey data were not collected, delinquency was averaged across years through tenth grade. This temporal ordering was necessary so as not to conflate the precursors and consequences of justice system involvement, as research has shown delinquent behavior to be a consequence of justice system involvement [20].

Past month drug use, including marijuana, powder or crack cocaine, amphetamines, tranquilizers, sedatives, psychedelics, and narcotics, was measured in the SSDP sample every year from sixth through tenth grades. A frequency value was calculated for each youth for each survey year through tenth grade. Prior drug use frequency was also measured so as to establish temporal ordering with incarceration, in the same manner as described above for delinquency. Prior drug use was only available through tenth grade, so average prior delinquency for those youth who had their first incarceration in grade 11 or 12 was calculated through tenth grade.

\section{Confounding Variables: Demographic Variables}

Ethnicity and gender were both self-reported by the youth. Family structure was a measure of whether the youth lived in a household with two biological parents (0) or a non-two parent household (1) and was reported by the youth's caregiver in fifth grade. Finally, poverty was a measure of whether the youth was eligible for free or reduced school lunch in fifth, sixth, or seventh grade.

\section{Confounding Variables: Behavioral Disinhibition}

Behavioral disinhibition was measured in eighth grade with five items assessing the frequency of impulsive and risky behavior. For example, youth were asked how many times they had done the following things: "do what feels good, regardless of the consequences" and "do something dangerous because someone dared you." The items were standardized and averaged to create the behavioral disinhibition scale used in these analyses (Cronbach's $\alpha=0.77$ ).

\section{Confounding Variables: Criminogenic Environment}

Four measures were used to capture youths' criminogenic environment. Family history of arrest was assessed with four variables. First, youth were asked if any of their siblings had ever been arrested. Youth's parents were also asked if they had ever been in trouble with the law, if their partner had ever been in trouble with the law, and finally, if any of their children, besides the SSDP respondent had ever been in trouble with the law. If any of these four items was endorsed from fifth through eighth grade, the youth was coded as (1) for family history of police contact. Youth who reported that at least one of their three best friends had ever been arrested in fifth through eighth grade were coded as (1) for the peer arrest variable, otherwise (0). If a youth reported having been in a gang at any point in fifth through eighth grades, he/she was coded (1), otherwise (0) for gang membership. Neighborhood criminogenic environment was assessed in eighth grade with an item that asked "How much does the following describe your neighborhood: Crime?" The four possible responses ranged from "not at all" to "a lot." 


\section{Confounding Variables: Prosocial Protective Factors}

The prosocial family environment variable consisted of 22 items that measured family management, involvement, bonding, and conflict (reverse coded). Examples of items included: "The rules in my family are clear," "Our family members get along well with each other," "On weekdays, how many meals does your family eat together each day?" and "Do you share your thoughts and feelings with your mother?" Each item was standardized and then averaged to create a composite measure. The average of fifth and sixth grades was used (Cronbach's $\alpha=0.84)$.

The prosocial peer environment variable measured the extent to which the youths' four best friends (in fifth grade) and three best friends (in sixth grade) attempted to excel in school. The question asked, "Does this person [first best friend] try to do well in school?" Again, items were standardized and averaged within grade. The average of fifth and sixth grades were used for these analyses (Cronbach's $\alpha=0.45$ ).

\section{Analytic Strategy}

The current study examined the consequences of juvenile incarceration for adult functioning. One of the greatest challenges when examining the life course consequences of incarceration is properly controlling for confounding variables: things that might have affected both the incarceration as well as subsequent later functioning. It can be argued that environmental and individual risks are causing both incarceration and subsequent negative outcomes in later life. We used two strategies to address this concern. First, the current study used a subsample of the original SSDP community sample: the 325 youth who ever experienced a police contact (either in self-report or in official records). Reducing the sample to only those who had ever had a police contact provided a similar comparison group of youth for assessing the effects of juvenile incarceration. Effectively, the sample studied here was limited to those who were at risk for incarceration.

Second, we used propensity score analysis [55] to address selection bias, as the assumption of ignorable treatment assignment is central to any research on treatment effects [56]. As noted by Yanovitzky et al. [57], when random assignment in not feasible (as is the case for examining incarceration consequences), propensity score analysis can be a very effective means of balancing the data. An advantage of propensity score analysis over multiple regression analysis is that it reduces covariates to a single score, which can increase statistical power and decrease the likelihood of encountering problems with multicollinearity.

In the current study, we used propensity score weighting, which involves estimating a propensity score, or the conditional probability of receiving the "treatment" of incarceration, and then using this score as a sampling weight in a weighted outcome analyses. One advantage to this method, compared to other methods such as matching, is that all of the study participants are retained, as each participant contributes a different amount of valuable information based on his/her propensity. In this way, we could estimate the average treatment effect of incarceration on measures of adult functioning. In many ways, this method is similar to using sampling weights, though the goal is to achieve internal validity rather than external validity [56]. 
It is important to note that, while propensity score analysis is a useful tool, there are certain limitations to this technique. As with other statistical models, propensity score models cannot account for any hidden selection bias (i.e., variables that affect selection into treatment but were not measured). Second, a propensity score is only as good as the variables used to estimate it. While we attempted to include as many relevant confounders as possible when estimating the propensity score, there are possibly other variables that could have also added information.

In the current study, 11 childhood risk and protective factors were used to estimate a propensity score (see Table 1). We chose variables that were related to juvenile incarceration at the $p<0.10$ level to include in the propensity score estimation model. As described by Guo and Fraser [56], the goal of this estimation step is to construct a model that will produce a propensity score that will adequately balance the two groups. Often this model-building step is an iterative process whereby the researcher includes quadratic and interaction terms into the model and then tests the balance until an adequate balancing score is achieved [58]. This is the process we used for the current analysis, and we were able to achieve balance between the "treatment" and "control" groups (see Table 1). The inverse of the propensity score was then used to weight the sample $(1 / p$ for the treatment group and $1 /(1-p)$ for the control group) when the outcomes of interest were regressed on incarceration. Multiple imputation was used to account for missing data. Across all variables used in the analysis, the average rate of missing data was $5.1 \%$. Results were combined from 40 imputed datasets as recommended by Graham [59] to estimate unbiased parameters and standard errors.

Table 1 Covariate balance post-propensity score weighting

\begin{tabular}{|c|c|c|c|c|c|c|}
\hline & \multicolumn{2}{|c|}{$\begin{array}{l}\text { Never incarcerated } \\
(n=217)\end{array}$} & \multicolumn{2}{|c|}{ Incarcerated $(n=108)$} & \multirow[b]{2}{*}{$p$ value } & \multirow[b]{2}{*}{$\begin{array}{l}\text { Standardized } \\
\text { mean difference }\end{array}$} \\
\hline & Mean (SE) & Percentage & Mean (SE) & Percentage & & \\
\hline Delinquency & $1.53(0.07)$ & & $1.55(0.11)$ & & 0.85 & 0.08 \\
\hline Drug use & $0.82(0.17)$ & & $0.88(0.19)$ & & 0.81 & 0.14 \\
\hline Family history of arrest & & 47.2 & & 55.7 & 0.29 & 0.17 \\
\hline Peer history of arrest & & 22.6 & & 24.3 & 0.80 & 0.04 \\
\hline Neighborhood crime & $1.0(0.08)$ & & $0.95(0.13)$ & & 0.74 & -0.15 \\
\hline Gang membership & & 18.5 & & 16.7 & 0.73 & -0.05 \\
\hline Prosocial peer environment & $-0.09(0.06)$ & & $-0.07(0.06)$ & & 0.85 & 0.07 \\
\hline Poverty & & 63.5 & & 58.5 & 0.55 & -0.10 \\
\hline Male gender & & 64.4 & & 62.3 & 0.80 & -0.04 \\
\hline \multicolumn{7}{|l|}{ Race/ethnicity } \\
\hline European American & & 37.9 & & 39.9 & 0.81 & 0.04 \\
\hline African American & & 35.2 & & 35.8 & 0.93 & 0.01 \\
\hline Asian American & & 20.1 & & 17.6 & 0.71 & -0.06 \\
\hline Native American & & 6.7 & & 6.6 & 0.95 & -0.01 \\
\hline Behavioral disinhibition & $0.21(0.06)$ & & $0.25(0.10)$ & & 0.73 & 0.15 \\
\hline
\end{tabular}




\section{Results}

\section{Covariate Balance}

Table 1 shows the post-weighting means and percentages for all confounding variables for the two groups: never incarcerated $(n=217)$ versus incarcerated $(n=108)$. After propensity score weighting was used to balance the sample, there were no statistically significant differences between the two groups on any of the confounding variables. In addition, many propensity score experts recommend using the standardized mean difference to assess balance. There has been no universally agreed upon cut point [60], but Guo and Fraser [56] assert that a difference above 0.20 signifies significant imbalance. For the current study, all of the standardized mean differences are below 0.20 , and most are below 0.10 .

\section{Model Results}

Table 2 shows the relationship between juvenile incarceration and adult outcomes at ages 27-33 both before propensity score weighting (column 1) and after (column 2). The odds ratios in column 1 represent the zero-order relationships between juvenile incarceration and adult outcomes. At the zero-order level, juvenile incarceration significantly predicts crime, incarceration, alcohol use problems, drug use problems, and welfare receipt in adulthood. After propensity score weighting, wherein the two groups are balanced on confounding variables, juvenile incarceration still significantly predicts incarceration, alcohol use problems, and welfare receipt. Specifically, those who were incarcerated in adolescence are almost four times more likely to experience incarceration in adulthood, more than two times more likely to have met criteria for alcohol abuse or dependence, and more than two times more likely to be receiving public assistance in adulthood than their counterparts with similar criminal propensity who had not be incarcerated in adolescence.

\section{Discussion and Future Directions}

Several interesting results and subsequent points of discussion emerged from this study. We found that the statistically significant negative consequences of juvenile incarceration include adult incarceration, alcohol use problems, and welfare receipt.

Table 2 Consequences of incarceration for adult functioning (odds ratios)

$* p<0.05 ; * * p<0.01$;

$* * * p<0.001$

\begin{tabular}{lll}
\hline & \multicolumn{2}{l}{ Incarcerated versus never incarcerated } \\
\cline { 2 - 3 } & Pre-weighting & Post-weighting \\
\hline Crime & $2.92^{* * *}$ & 1.88 \\
Incarceration & $8.94 * * *$ & $3.70^{* *}$ \\
Alcohol & $1.98^{* *}$ & $2.28^{*}$ \\
Drugs & $2.15^{* *}$ & 1.25 \\
Anxiety & 0.54 & 0.45 \\
Depression & 0.70 & 0.54 \\
Welfare & $2.10^{* *}$ & $2.21 *$ \\
\hline
\end{tabular}


Interestingly, there was no evidence that those who were incarcerated as youth were significantly more likely to be committing crime in adulthood than their counterparts who had a police contact in adolescence but were not incarcerated, though they were more likely to be incarcerated as adults.

McAra and McVie [61] examined the cyclical relationships among offending, patterns of juvenile justice system involvement, and recidivism. They reported on how "labelling processes within agency working cultures serve to recycle certain categories of children into the youth justice system" (p. 315). For these "certain categories of youth," system involvement often begets more system involvement and exposure to the most serious sanctions (including incarceration), regardless of actual offending behavior. The results of the current study provide evidence that this pattern of labeling observed in adolescence may also be occurring across developmental domains into adulthood. That is, once youth are incarcerated, they might become increasingly enmeshed in and attached to the justice system as they transition into adulthood. However, since we did not find evidence that those who were incarcerated as adolescence were more likely to be committing crime in adulthood, more research needs to be done to test how the criminal label is operating during the transition to adulthood, as labeling theory would assert that the criminal label would increase the propensity for crime (through internalization of the label, increased association with antisocial peers, and decreases in opportunity structures).

Also interesting is the finding that the consequences of juvenile incarceration reach beyond the criminal domain to predict substance use and welfare receipt. This is not surprising, given the earlier discussion about cumulative disadvantage and the "snowballing" effects of a criminal label. However, the empirical evidence was lacking, given the limited availability of longitudinal studies capable of answering this question. Again, future research should test the mediators of these relationships.

Finally, there is reason to suspect that the consequences of incarceration might vary for different racial/ethnic groups or by gender. While that was not the focus of the current study, and our statistical power to detect group differences was limited, this is a very interesting research question that should be pursued in future studies.

\section{Limitations}

One limitation of this study was the sample size. While limiting the sample to only those who had ever had a police contact decreased our sample size and statistical power, it greatly strengthened our ability to make empirically supported conclusions about the direct consequences of juvenile incarceration. In addition, while a strength of this study was using a community sample (thus allowing for comparisons of those who had been incarcerated with those who had not), the sample came from a specific region in the USA. This could possibly limit the generalizability of its findings to other parts of the country. Future research should attempt to replicate study findings with a larger, nationally representative sample.

\section{Conclusions}

Krisberg and Marchionna [62] examined the attitudes of US voters toward the juvenile justice system and found that $91 \%$ of participants believe that rehabilitation and 
treatment will reduce crime. Furthermore, more that $80 \%$ believe that rehabilitation services will save taxpayers money in the future. While the majority of the public support rehabilitation and treatment in the juvenile justice system, research, including the current study, is illuminating the numerous and far-reaching consequences of incarceration. Davis et al. [32] write that successful implementation of juvenile justice must occur within the scope of social justice. In other words, the juvenile justice system must strike a balance between public safety and rehabilitation for youth [63]. However, it appears that the juvenile justice system is, in fact, creating worse outcomes for many youth as they transition into adulthood, hindering their chances of becoming productive members of society. One of the strongest relationships found in this current study is that between adolescent incarceration and adult incarceration. Even when controlling for prior risk factors, this relationship remained. It appears that, for some youth, juvenile incarceration is not a sanction that is limited to adolescence but an event that could likely change the course of their lives for the worse.

Perhaps, Cullen and Jonson [64] said it most eloquently when writing, "The chief issue is not non-intervention but how to intervene in a way that does not have iatrogenic effects" (p. 69). Hopefully, the results of the current study, that juvenile incarceration indeed has unique negative effects on adult functioning, will motivate researchers and practitioners to continue pursuing juvenile justice system reform and seeking appropriate alternatives to incarceration that do not jeopardize public safety.

\section{References}

1. McCord, J., Widom, C. S., \& Crowell, N. A. (2001). Juvenile crime, juvenile justice. Washington: National Academy Press.

2. Myers, D. M., \& Farrell, A. F. (2008). Reclaiming lost opportunities: applying public health models in juvenile justice. Children and Youth Services Review, 30(10), 1159-1177.

3. Hockenberry, S. (2014). Juveniles in residential placement, 2011. Juvenile Offenders and Victims: National Report Series. Washington, DC: Office of Juvenile Justice and Delinquency Prevention.

4. Annie E. Casey Foundation (2013). Youth incarceration in the United States. Baltimore, MD. Retrieved January 28, 2015 from http://www.aecf.org/resources/youth-incarceration-in-the-united-states/

5. Greve, W. (2001). Imprisonment of juveniles and adolescents: deficits and demands for developmental research. Applied Developmental Science, 5(1), 21-36.

6. Elder, G. H., Jr. (Ed.). (1985). Life course dynamics: trajectories and transitions, 1968-1980. Ithaca: Cornell University Press.

7. Wheaton, B., \& Gotlib, I. H. (1997). Trajectories and turning points over the life course: concepts and themes. In I. H. Gotlib \& B. Wheaton (Eds.), Stress and adversity over the life course: trajectories and turning points (pp. 1-28). Cambridge: Cambridge University Press.

8. Sampson, R. J., \& Laub, J. H. (1992). Crime and deviance in the life course. Annual Review of Sociology, $18,63-84$.

9. Lemert, E. M. (1951). Social pathology: a systematic approach to the theory of sociopathic behavior. New York: McGraw-Hill.

10. Tannenbaum, F. (1938). Crime and community. New York: Columbia University Press.

11. Gilman, A. B., Hill, K. G., Kim, B. K. E., Nevell, A., Hawkins, J. D., \& Farrington, D. P. (2014). Understanding the relationship between self-reported offending and official criminal charges across early adulthood. Criminal Behaviour and Mental Health, 24(4), 229-240.

12. Sampson, R. J., \& Laub, J. H. (1997). A life-course theory of cumulative disadvantage and the stability of delinquency. In T. P. Thornberry (Ed.), Developmental theories of crime and delinquency (pp. 133-161). New Brunswick: Transaction Publishers.

13. Lanctot, N., Cernkovich, S. A., \& Giordano, P. C. (2007). Delinquent behavior, official delinquency, and gender: consequences for adulthood functioning and well-being. Criminology, 45(1), 131-157. 
14. Barrick, K. (2014). A review of prior tests of labeling theory. In D. P. Farrington \& J. Murray (Eds.), Labeling theory: empirical tests (pp. 89-112). New Brunswick: Transaction Publishers.

15. Bernburg, J. G., Krohn, M. D., \& Rivera, C. J. (2006). Official labeling, criminal embeddedness, and subsequent delinquency: a longitudinal test of labeling theory. Journal of Research in Crime and Delinquency, 43(1), 67-88.

16. Farrington, D. P. (1977). The effects of public labeling. British Journal of Criminology, 17(2), 112-125.

17. Johnson, L. M., Simons, R. L., \& Conger, R. D. (2004). Criminal justice system involvement and continuity of youth crime: a longitudinal analysis. Youth \& Society, 36(1), 3-29.

18. Wiley, S. A., Slocum, L. A., \& Esbensen, F. A. (2013). The unintended consequences of being stopped or arrested: an exploration of the labeling mechanisms through which police contact leads to subsequent delinquency. Criminology, 51(4), 927-966.

19. Lopes, G., Krohn, M. D., Lizotte, A. J., Schmidt, N. M., Vasquez, B. E., \& Bernburg, J. G. (2012). Labeling and cumulative disadvantage: the impact of formal police intervention on life chances and crime during emerging adulthood. Crime \& Delinquency, 58(3), 456-488.

20. Bernburg, J. G., \& Krohn, M. D. (2003). Labeling, life chances, and adult crime: the direct and indirect effects of official intervention in adolescence on crime in early adulthood. Criminology, 41(4), 1287-1318.

21. Becker, H. S. (1963). Outsiders: studies in the sociology of deviance. London: Free Press of Glencoe.

22. Rodriguez, N. (2013). Concentrated disadvantage and the incarceration of youth: examining how context affects juvenile justice. Journal of Research in Crime and Delinquency, 50(2), 189-215.

23. Gold, M., \& Williams, R. (1969). National study of the aftermath of apprehension. Prospectus, 3, 3-11.

24. Petitclerc, A., Gatti, U., Vitaro, F., \& Tremblay, R. E. (2013). Effects of juvenile court exposure on crime in young adulthood. Journal of Child Psychology and Psychiatry, 54(3), 291-297.

25. Bushway, S. D. (1998). The impact of an arrest on the job stability of young white American men. Journal of Research in Crime and Delinquency, 35(4), 454-479.

26. Wiesner, M., Kim, H. K., \& Capaldi, D. M. (2010). History of juvenile arrests and vocational career outcomes for at-risk young men. Journal of Research in Crime and Delinquency, 47(1), 91-117.

27. Apel, R., \& Sweeten, G. (2010). The impact of incarceration on employment during the transition to adulthood. Social Problems, 57(3), 448-479.

28. Freeman, R. B. (1987). The relation of criminal activity to Black youth employment. The Review of Black Political Economy, 16(1-2), 99-107.

29. Huebner, B. M. (2005). The effect of incarceration on marriage and work over the life course. Justice Quarterly, 22(3), 281-303.

30. Laub, J. H., \& Sampson, R. J. (2003). Shared beginnings, divergent lives: delinquent boys to age 70. Cambridge: Harvard University Press.

31. Tanner, J., Davies, S., \& O'Grady, B. (1999). Whatever happened to yesterday's rebels? Longitudinal effects of youth delinquency on education and employment. Social Problems, 46(2), 250-274.

32. Davis, A., Tsukida, C., Marchionna, S., \& Krisberg, B. (2008). The declining number of youth in custody in the juvenile justice system. FOCUS. Oakland: National Council on Crime and Delinquency.

33. Western, B. (2002). The impact of incarceration on wage mobility and inequality. American Sociological Review, 67(4), 526-546.

34. Geller, A., \& Curtis, M. A. (2011). A sort of homecoming: incarceration and the housing security of urban men. Social Science Research, 40(4), 1196-1213.

35. Huebner, B. M. (2007). Racial and ethnic differences in the likelihood of marriage: the effect of incarceration. Justice Quarterly, 24(1), 156-183.

36. Lopoo, L. M., \& Western, B. (2005). Incarceration and the formation and stability of marital unions. Journal of Marriage and Family, 67(3), 721-734.

37. Massoglia, M., Remster, B., \& King, R. D. (2010). Stigma or separation? Understanding the incarcerationdivorce relationship. Social Forces, 90(1), 133-155.

38. Massoglia, M. (2008). Incarceration as exposure: the prison, infectious disease, and other stress-related illnesses. Journal of Health and Social Behavior, 49(1), 56-71.

39. Massoglia, M. (2008). Incarceration, health, and racial disparities in health. Law \& Society Review, 42(2), 275-306.

40. Schnittker, J., \& John, A. (2007). Enduring stigma: the long-term effects of incarceration on health. Journal of Health and Social Behavior, 48(2), 115-130.

41. Sameroff, A. J., Bartko, W. T., Baldwin, A., Baldwin, C., \& Seifer, R. (1998). Family and social influences on the development of child competence. In M. Lewis \& C. Feiring (Eds.), Families, risk, and competence (pp. 161-185). Mahwah, NJ: Erlbaum.

42. Davies, S., \& Tanner, J. (2003). The long arm of the law: effects of labeling on employment. Sociological Quarterly, 44(3), 385-404. 
43. Collins, W. A., \& Steinberg, L. (2006). Adolescent development in interpersonal context. In W. Damon \& N. Eisenberg (Eds.), Handbook of child psychology (Vol. 4: Socioemotional processes, pp. 1003-1067). New York: Wiley.

44. Abram, K. M., Choe, J. Y., Washburn, J. J., Romero, E. G., \& Teplin, L. A. (2009). Functional impairment in youth three years after detention. Journal of Adolescent Health, 44(6), 528-535.

45. Hjalmarsson, R. (2009). Juvenile jails: a path to the straight and narrow or to hardened criminality? Journal of Law \& Economics, 52(4), 778-808.

46. Aizer, A., \& Doyle, J. J. (2013). Juvenile incarceration, human capital and future crime: evidence from randomly-assigned judges. NBER working paper series. Cambridge: National Bureau of Economic Research.

47. Hjalmarsson, R. (2008). Criminal justice involvement and high school completion. Journal of Urban Economics, 63(2), 613-630.

48. White, H. R., Shi, J., Hirschfield, P., Mun, E. Y., \& Loeber, R. (2010). Effects of institutional confinement for delinquency on levels of depression and anxiety among male adolescents. Youth Violence and Juvenile Justice, 8(4), 295-313.

49. Pettit, B., \& Western, B. (2004). Mass imprisonment and the life course: race and class inequality in US incarceration. American Sociological Review, 69(2), 151-169.

50. Hawkins, J. D., Catalano, R. F., Kosterman, R., Abbott, R., \& Hill, K. G. (1999). Preventing adolescent health-risk behaviors by strengthening protection during childhood. Archives of Pediatrics and Adolescent Medicine, 153(3), 226-234.

51. Catalano, R. F., Kosterman, R., Hawkins, J. D., Newcomb, M. D., \& Abbott, R. D. (1996). Modeling the etiology of adolescent substance use: a test of the social development model. Journal of Drug Issues, 26(2), 429-455.

52. Huang, B., Kosterman, R., Catalano, R. F., Hawkins, J. D., \& Abbott, R. D. (2001). Modeling mediation in the etiology of violent behavior in adolescence: a test of the social development model. Criminology, 39(1), 75-107.

53. Guttmannova, K., Hill, K. G., Bailey, J. A., Lee, J. O., Hartigan, L. A., Hawkins, J. D., et al. (2012). Examining explanatory mechanisms of the effects of early alcohol use on young adult alcohol dependence. Journal of Studies on Alcohol and Drugs, 73(3), 379-390.

54. American Psychiatric Association. (1994). Diagnostic and statistical manual of mental disorders (4th ed.). Washington: American Psychiatric Association.

55. Rosenbaum, P. R., \& Rubin, D. B. (1983). The central role of the propensity score in observational studies for causal effects. Biometrika, 70, 41-55.

56. Guo, S., \& Fraser, M. W. (2014). Propensity score analysis: statistical methods and applications. Los Angeles: Sage.

57. Yanovitzky, I., Hornik, R., \& Zanutto, E. (2008). Estimating causal effects in observational studies: the propensity score approach. In A. F. Hayes, M. D. Slater, \& L. B. Snyder (Eds.), The SAGE sourcebook of advanced data analysis methods for communication (pp. 159-184). Los Angeles: Sage.

58. Rosenbaum, P. R., \& Rubin, D. B. (1984). Reducing bias in observational studies using subclassification on the propensity score. Journal of the American Statistical Association, 79(387), 516-524.

59. Graham, J. W. (2009). Missing data analysis: making it work in the real world. Annual Review of Psychology, 60, 549-576.

60. Austin, P. C. (2008). Goodness-of-fit diagnostics for the propensity score model when estimating treatment effects using covariate adjustment with the propensity score. Pharmacoepidemiology and Drug Safety, 17(12), 1202-1217.

61. McAra, L., \& McVie, S. (2007). Youth justice? The impact of system contact on patterns of desistance from offending. European Journal of Criminology, 4(3), 315-345.

62. Krisberg, B., \& Marchionna, S. (2007). Attitudes of US voters towards youth crime and the justice system. FOCUS. Oakland: National Council on Crime and Delinquency.

63. Kurlychek, M., Torbet, P., \& Bozynski, M. (1999). Focus on accountability: best practices for juvenile court and probation. Juvenile Accountability Incentive Block Grants Program Bulletin. Washington: Office of Juvenile Justice and Delinquency Prevention.

64. Cullen, F. T., \& Jonson, C. L. (2014). Labeling theory and correctional rehabilitation: beyond unanticipated consequences. In D. P. Farrington \& J. Murray (Eds.), Labeling theory: empirical tests (pp. 63-88). New Brunswick: Transaction Publishers. 